\title{
Posthepatectomy Bile Leakage: How to Manage
}

\author{
Lisette T. Hoekstra Thomas M. van Gulik Dirk J. Gouma Oliver R. Busch \\ Department of Surgery, Academic Medical Center, University of Amsterdam, Amsterdam, The Netherlands
}

\section{Key Words}

Bile leakage $\cdot$ Liver resection - Percutaneous transhepatic biliary drainage $\cdot$ Endoscopic stenting

\begin{abstract}
Background: Biliary leakage after liver resection continues to be reported. Management of bile leakage has changed in recent years, with nowadays non-surgical procedures as the preferred treatment. Methods: Biliary leakage and management were assessed in 381 patients who underwent liver resection between January 2005 and April 2011. Results: The overall rate of biliary leakage after liver resection was $5.0 \%$, with a higher incidence in patients who had undergone concomitant hepaticojejunostomy (HJ; 13.6 vs. 3.2\%). Hospital stay $(p=0.047)$, major resections $(p=0.018)$, operation time $(p=0.011)$, and relaparotomy $(p=0.002)$ were risk factors for postoperative bile leakage. Multivariate analysis identified relaparotomy as an independent factor (OR 4.216, $\mathrm{p}=0.034$ ). Bile leakage in patients without $\mathrm{HJ}(\mathrm{n}=10)$ was managed in 6 patients by percutaneous transhepatic biliary drainage (PTD), and in 3 patients by endoscopic drainage. One patient was treated surgically. All patients with an $\mathrm{HJ}$ and postoperative bile leakage $(n=9)$ underwent PTD. Conclusion: The incidence of posthepatectomy biliary leakage has decreased over time, while PTD and endoscopic stenting are effective treatment modalities. PTD is the treatment of choice in bile leakage after resection combined with $\mathrm{HJ}$.
\end{abstract}

Copyright $\odot 2012$ S. Karger AG, Basel
(C) 2012 S. Karger AG, Basel 0253-4886/12/0291-0048\$38.00/0

Fax +41613061234 E-Mail karger@karger.ch www.karger.com

\section{Introduction}

The numbers of hepatic resections are increasing. Although less overall postoperative complications are reported, biliary leakage after liver surgery continues to be documented with unchanged incidences, ranging from 3.6 [1] to 33\% [2]. Biliary leakage may lead to intraperitoneal septic complications, liver failure and ultimately, death [3]. The incidence and management of bile leakage after partial liver resection in our Department from 1992 to 2004 has been reported by Erdogan et al. [4, 5]. However, the management of this complication has changed from relaparotomies to mainly non-surgical interventions in the last years, potentially leading to a decrease in procedure-related complications and better outcomes. Besides conservative treatment such as drainage and antibiotics, several management strategies are available, such as percutaneous and endoscopic drainage of bile leakage. The aims of this study were to evaluate the efficacy of management of bile leakage after liver resection, to examine the incidence and outcomes of bile leakage in patients with and without hepaticojejunostomy $(\mathrm{HJ})$, and to assess the evolution of the treatment approach of postresectional biliary leakage in a recent period of time (2005-2011) as compared to the previous reported period 1992-2004.
Lisette T. Hoekstra, MD

Department of Experimental Surgery, Academic Medical Center

University of Amsterdam, Meibergdreef 9

NL-1105 AZ Amsterdam (The Netherlands)

Tel. +31 20566 5569, E-Mail L.T.Hoekstra@ amc.uva.nl 


\section{Methods}

A retrospective analysis was performed of patients who received a liver resection in our Department between January 2005 and April 2011. This group was divided into patients who had undergone liver resection with or without concomitant bile duct resection and biliary-enteric reconstruction, usually an HJ. In all patients, demographics, preoperative data, operative variables, complications (including postoperative bile leakage and management), and revision surgery were evaluated retrospectively.

\section{Definitions}

Liver resections were classified as major, defined as resections of more than three Couinaud's segments, or minor, defined as resections of less than three liver segments, including wedge resections and metastectomies. Bile leakage was defined as continuous drainage of bile from the abdominal drain ( $>1$ day after surgery), and/or leakage or a bile collection demonstrated on radiological imaging (ERC, US, CT), and/or detection of a bile collection drained percutaneously or during relaparotomy, as has been described previously [5]. Bile leakage originating from the cut surface of the remnant liver was reported as peripheral bile leakage, and leakage from the extrahepatic bile ducts as central bile leakage.

No commonly used definition of posthepatectomy bile leakage has been established, resulting in a wide range of reported bile leakage rates. However, Koch et al. [6] recently published a grading system of bile leakage after hepatobiliary and pancreatic surgery. In-hospital mortality was defined as death within 30 days from operation or thereafter if the patient was still hospitalized.

\section{Management of Postoperative Bile Leakage}

Conservative management (prolonged drainage and antibiotic treatment in case of persistent fever) constituted initial treatment of postoperative bile leakage. Additionally, percutaneous drainage, usually with antimicrobial therapy, was undertaken if an intra-abdominal bile collection sustained, as identified by abdominal ultrasonography and/or CT scan. In case of persistence of biliary leakage, ERC with sphincterotomy and stent placement in the CBD was undertaken. If non-surgical treatment proved not to be effective, the clinical situation of the patient worsened, or biliary peritonitis developed, a relaparotomy with drainage of the bilioma/bile leak was considered.

\section{Statistical Analysis}

Values are expressed as means $\pm \mathrm{SD}$, unless otherwise stated. The differences among the groups were compared using the twotailed unpaired Student $t$ test for continuous parametric data. The Mann-Whitney $U$ test was used for continuous nonparametric data. Categorical data were compared using the Fisher exact test or $\chi^{2}$ test, as appropriate. Firstly, univariate analysis was performed to examine variables significantly correlated with postoperative bile leakage. Significant factors on univariate analysis were then analyzed by stepwise logistic regression to identify independent predictors of bile leakage. The results were considered to be of statistical significance when $\mathrm{p}<0.05$. The data were analyzed by statistical software (SPSS 18.0.0; SPSS, Chicago, Ill., USA) and GraphPad Prism (Graph-Pad Software, San Diego, Calif., USA).

Posthepatectomy Bile Leakage

\section{Results}

In the most recent period from 2005 to 2011, 381 hepatectomies were performed, compared to 286 liver resections in the previous period between 1992 and 2004. Colorectal metastases were seen most frequently, in 132 of all patients (34.6\%) in the first group (2005-2011) and $51.7 \%(121 / 234)$ in the second $(1992-2004 ; \mathrm{p}<0.001)$. A higher rate $(30.2 \%, 115 / 381$ vs. $26.5 \%, 62 / 234)$ of benign lesions was seen in the patients operated between 2005 and $2011(\mathrm{p}<0.001)$.

Overall, the complication rate of biliary leakage after liver resection in the more recent years (2005-2011) was $5.0 \%$ (19/381 patients) compared to $10.8 \%$ (31/286 patients) in the previous period (1992-2004) [5]. In the more recent period, the incidence of bile leakage was much higher in patients who underwent concomitant $\mathrm{HJ}$ as compared to those without HJ, i.e. $13.6 \%(\mathrm{n}=66)$ and $3.2 \%(\mathrm{n}=315)$, respectively.

In the more recent group, all patients with postoperative bile leakage had significantly longer hospital stay (median 15.0, IQR 11.0-20.0 days vs. 9.0, IQR 7.0-12.3 days; $\mathrm{p}<0.001$ ), had undergone more major resections (74\%, $14 / 19$ vs. $44 \%, 151 / 340 ; \mathrm{p}=0.013)$, had significantly longer operation time (median 378, IQR 228-439 min vs. 227, IQR 155-349 min; $\mathrm{p}=0.003$ ), and more often underwent a relaparotomy $(21 \%, 4 / 19$ vs. $3.9 \%, 14 / 262$; $\mathrm{p}=$ 0.009), compared to patients without biliary leak. No significant differences were found for age, gender, comorbidity, compromised liver, preoperative portal vein embolization, unresectability, readmission time, or in-hospital mortality. However, taking into account only the patients without $\mathrm{HJ}$, significant differences were found for age $(p=0.012)$, and relaparotomy $(p<0.001)$. No other significant differences were seen. These patient characteristics are shown in table 1.

In the more recent group, hospital stay (OR 1.031, $\mathrm{p}=$ 0.047), major resections ( $\mathrm{OR} 3.505, \mathrm{p}=0.018$ ), operation time (OR 1.003, $\mathrm{p}=0.011$ ), and relaparotomy (OR 6.629, $\mathrm{p}=0.002)$ were overall risk factors associated with postoperative bile leakage, as determined by univariate analysis. Multivariate analysis identified only relaparotomy as independent factor that was significantly correlated with the occurrence of bile leakage (OR 4.216, $\mathrm{p}=0.034$, 95\% CI 1.11-15.97). In patients without HJ, in univariate analysis, relaparotomy (OR 25.714, $\mathrm{p}<0.001$ ) and age (OR $0.950, \mathrm{p}=0.016$ ) were significant factors for biliary leak, with relaparotomy again as only independent factor (OR 19.599, $\mathrm{p}=0.001 ; 95 \%$ CI 3.48-110.38). The distribution of bile leakage according to type of hepatic re- 
Table 1. Patient characteristics pre- and postoperatively (without HJ; 2005-2011)

\begin{tabular}{lccl}
\hline Variable & No bile leakage & Bile leakage & $\begin{array}{l}\mathrm{p} \\
\text { value }\end{array}$ \\
\hline Total & $305 / 315(96.8)$ & $10 / 315(3.2)$ & \\
Age, years & $55.1 \pm 14.6$ & $43.0 \pm 22.1<0.001^{*}$ \\
Males & $121 / 305(39.7)$ & $3 / 10(30)$ & 0.745 \\
Comorbidity & $290 / 305(95.1)$ & $10 / 10(100)$ & 1.000 \\
Compromised liver & $180 / 305(59.0)$ & $8 / 10(80.0)$ & 0.326 \\
$\quad$ Cirrhosis & 12 & 0 & \\
$\quad$ Steatosis & 106 & 5 & \\
$\quad$ Fibrosis & 95 & 3 & \\
$\quad$ Cholestasis & 23 & 2 & \\
Hospital stay, days & $9.0 \pm 9.1$ & $12.0 \pm 10.3$ & 0.100 \\
Portal vein embolization & $20 / 305(6.6)$ & $2 / 10(20.0)$ & 0.149 \\
Major resection & $103 / 284(36.3)$ & $5 / 10(50)$ & 0.506 \\
Unresectable & $21 / 305(6.9)$ & $0 / 10(0)$ & 1.000 \\
Operation time, min & $213 \pm 110$ & $248 \pm 100$ & 0.146 \\
Relaparotomy & $5 / 305(1.6)$ & $3 / 10(30.0)$ & $0.001^{*}$ \\
Readmission time, days & $9(4-42)$ & $9(5-12)$ & 1.000 \\
Intrahospital mortality & $12 / 305(3.9)$ & $0 / 10(0)$ & 1.000 \\
\hline
\end{tabular}

Asterisk indicates statistically significant difference.

Figures in parentheses indicate percentages or IQR.

Values for age are expressed as mean $\pm \mathrm{SD}$, and for hospital stay, operation time and readmission time as mean $+\mathrm{SD}$. section is depicted in table 2. Most bile leakages were seen in patients who had undergone right hemihepatectomy.

Between 2005 and 2011, bile leakages $(\mathrm{n}=10)$ in patients without $\mathrm{HJ}$ were non-surgically managed in 9 patients $(90 \%)$ and surgically in one patient (10\%). The latter was a 4-year-old child with a traumatic liver laceration and leakage of the extrahepatic bile duct, which was sutured. However, bile leakage persisted; therefore, a left hemihepatectomy was ultimately performed (hospital stay 30 days). Six patients were managed by percutaneous biliary drainage (PTD) with a mean hospital stay of 9.8 \pm 1.4 days and 3 patients by endoscopic drainage (fig. 1) with a mean hospital stay of $12.0 \pm 3.0$ days. An $\mathrm{HJ}$ had to be performed in one patient after a right hemihepatectomy with postoperative bile leakage due to transection of an aberrant isolated left segmental bile duct arising from the right ductal system, which could obviously not be treated by endoscopic retrograde cholangiopancreatography (ERCP) and placement of an endoprosthesis. Another patient developed persistent bile leakage after extirpation of an intrahepatic choledochal cyst. During
Table 2. Type of liver resection in patients with bile leakage (20052011)

\begin{tabular}{lll}
\hline Surgery & $\begin{array}{l}\text { Without HJ } \\
(\mathrm{n}=10)\end{array}$ & $\begin{array}{l}\text { With HJ } \\
(\mathrm{n}=9)\end{array}$ \\
\hline $\begin{array}{l}\text { Major } \\
\quad \text { Right hemihepatectomy }\end{array}$ & $4(40 \%)$ & $5(56 \%)$ \\
$\quad$ Right extended hemihepatectomy & 0 & 0 \\
$\quad$ Left hemihepatectomy & 0 & $2(22 \%)$ \\
$\quad$ Left extended hemihepatectomy & 0 & 0 \\
$\begin{array}{l}\text { Minor } \\
\text { 1-2 segments }\end{array}$ & $3(30 \%)$ & $1(11 \%)$ \\
$\quad$ Wedge resection & 0 & 0 \\
$\quad$ Other & $3(30 \%)$ & $1(11 \%)$ \\
\hline
\end{tabular}

Table 3. Treatment of bile leakage over time in patients without and with HJ (2005-2011)

\begin{tabular}{|c|c|c|}
\hline Treatment bile leakage & $\begin{array}{l}\text { Without HJ } \\
(\mathrm{n}=10)\end{array}$ & $\begin{array}{l}\text { With HJ } \\
(\mathrm{n}=9)\end{array}$ \\
\hline Percutaneous radiological drainage & $6(60 \%)$ & $9(100 \%)$ \\
\hline Endoscopic drainage & $3(30 \%)$ & 0 \\
\hline Conservative treatment & 0 & 0 \\
\hline Sutured & $1(10 \%)$ & 0 \\
\hline
\end{tabular}

ERCP, there was no connection between the central bile duct and the bile ducts of the right liver. Therefore, a right hemihepatectomy was performed, again complicated by bile leakage from the proximal end of the left main duct. Stent placement during ERCP was required twice (after 11 and 21 days) in this patient. Finally, the stent was removed after 83 days. None of the patients was managed medically. All of the patients with an $\mathrm{HJ}$ and postoperative bile leakage $(n=9)$ underwent PTD. All treatment strategies are summarized in table 3.

Of the previous series (1992-2004), including only patients who had liver resection without $\mathrm{HJ}$, all patients $(\mathrm{n}=16)$ with postoperative bile leakage were managed non-surgically. In 13 patients (81.3\%), an intervention was carried out; 4 (25\%) patients were treated by percutaneous radiological drainage with a mean duration of 13 days, and 9 (56.3\%) patients were managed by endoscopic drainage with a stent (mean 11 days). The remaining 3 patients (18.8\%) were managed conservatively, and bile leakage resolved after a maximum time of 18 days.

No in-hospital mortality was seen in patients with bile leakage after liver resection with or without HJ. An over- 

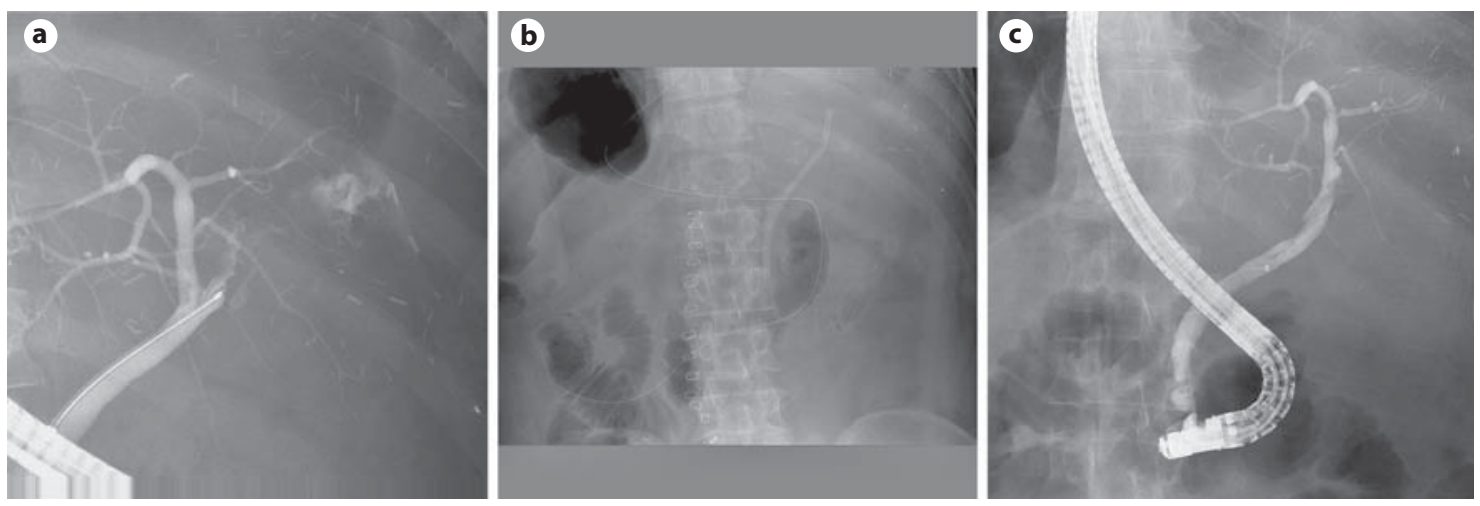

Fig. 1. a Endoscopic retrograde cholangiopancreaticography showing biliary leakage of the stump of the right hepatic duct after right hemihepatectomy. b ERCP with stent placement. c Six weeks later, bile leakage subsided.

Table 4. Complications and relaparotomies after initial treatment, listed according to diagnosis (2005-2011)

\begin{tabular}{llll}
\hline Diagnosis & Initial treatment & Complication & Relaparotomy \\
\hline Colorectal metastases & Percutaneous drainage & Subphrenic abscess & Drainage \\
Focal nodular hyperplasia & ERCP & Persistent bile leakage & HJ \\
Choledochal cyst & ERCP & Persistent bile leakage & Right hemihepatectomy \\
Traumatic laceration & Suture & Persistent bile leakage & Left hemihepatectomy \\
\hline
\end{tabular}

view of the relaparotomies is shown in table 4 . In the recent period 2005-2011, of the patients without HJ who did not have postoperative bile leakage (table 1), 5 (1.6\%) underwent a relaparotomy, and 12 (3.8\%) died in the hospital, compared to 3.2 and $2.8 \%$, respectively, in the preceding period 1992-2004.

According to the abovementioned system proposed by Koch et al. [6], in our study 16 patients (7 patients without $\mathrm{HJ}$, and 9 patients with $\mathrm{HJ}$ ) belonged to grade $\mathrm{B}$ and 3 patients (without $\mathrm{HJ}$ ) to grade $\mathrm{C}$. No grade A bile leakages were observed (table 5). This grading system is, therefore, useful in selecting patients with postoperative bile leakage who are candidates for radiological intervention (grade B) or laparotomy (grade C).

Although no patients were managed conservatively between 2005 and 2011, in $18.8 \%$ of patients treated in the previous period (1992 and 2004) the bile leakages resolved spontaneously, thus leaving the grade A patients for conservative treatment. The definition of Koch et al. [6] is not only based on the need for radiological intervention or relaparotomy; a three times higher concentration of bilirubin in the drain or intra-abdominal fluid compared to the serum bilirubin concentration on the same day is used. In our series (2005-2011), bilirubin concentration in the drain fluid was measured in only 6 patients, 2 of whom showed a three times greater value in the abdominal drain fluid. In our opinion, assessment of bilirubin concentration in the drain fluid has no additional value in this grading system. Regarding the internationally validated classification system introduced in 2004 by Dindo et al. [7], 16 patients (7 patients without $\mathrm{HJ}$ and 9 patients with $\mathrm{HJ}$ ) in our analysis were classified as grade IIIA, and 3 patients as grade IIIB, which is similar to the group of Koch et al. [6]. In all, these classification systems are effective and may facilitate the evaluation of therapeutic strategies for biliary complications. Nevertheless, it is important to note that patients with minor bile leakage may not have been included because of spontaneous resolution of the bile leak.

\section{Discussion}

The incidence of posthepatectomy biliary leakage has decreased in recent years from 10.8 to $5.0 \%$. Patients in whom liver resections were performed with concomitant 
Table 5. Proposal of the International Study Group of Liver Surgery for grading bile leakage after hepatobiliary surgery

\begin{tabular}{llc}
\hline Grade & Description & AMC \\
\hline A & $\begin{array}{l}\text { Bile leakage requiring no or little change in } \\
\text { patient's clinical management }\end{array}$ & 0 \\
\hline B & $\begin{array}{l}\text { Bile leakage requiring a change in patient's } \\
\text { clinical management (e.g. additional diagnostic } \\
\text { or interventional procedures) but manageable } \\
\text { without relaparotomy, or a grade A bile leakage } \\
\text { lasting for >1 week }\end{array}$ \\
\hline C & Bile leakage requiring relaparotomy & 3 \\
\hline
\end{tabular}

$\mathrm{AMC}=$ Academic Medical Center.

$\mathrm{HJ}$ showed a higher rate of postoperative bile leakage in our series (2005-2011: 13.6 vs. 3.2\% and 1992-2004: 28.9 vs. $6.8 \%)$. Obviously, these patients had a higher risk of biliary leakage because of the additional bilioenteric anastomosis. In patients with only liver resection, bile leakage from the transected liver surface or from intraoperative ductal injury of the central bile ducts was the cause of postoperative bile leakage. Bile leakage after hepatectomy is still one of the most frequently reported complications after liver resection, with incidences reported in the literature of $3.6 \%$ in patients without biliary anastomoses to $33 \%$ in patients with cholangiocellular carcinoma also without biliary reconstruction. In this study, the incidence of bile leakage in patients without $\mathrm{HJ}$ is in the lower limits of previously reported results.

To our knowledge, only few studies published the results of bile leakage after liver resection with concomitant biliary reconstruction $[8,9]$. A recent report showed the results of patients who underwent liver resection with biliary reconstruction compared to patients without biliary anastomosis [8]. Bile leakage was seen in 21.0 and 4.6\%, respectively; an almost similar finding as in our study.

Many authors reported that conservative management is the preferred treatment in patients with postoperative bile leakage after liver resection without $\mathrm{HJ}$, citing high success rates (up to 76.2\%) [8]. Others also have suggested conservative management in patients with bile leakage after liver resection with $\mathrm{HJ}[9,10]$. In our series, no patients in the period 2005-2011 were managed without intervention (PTD/ERCP). However, there is a possible bias because bile leakages may have resolved spontaneously without having been noted during admission. Non-surgical treatment is becoming the preferred ap-

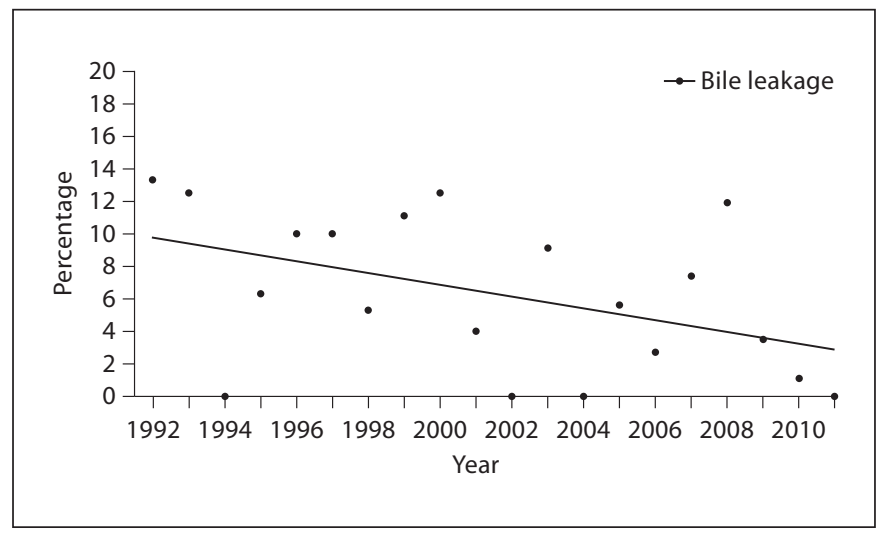

Fig. 2. The incidence of bile leakage decreases over time.

proach in the management of postoperative bile leakage [11]. This is confirmed by the results of this study, in which all patients with bile leakage were successfully treated by percutaneous or endoscopic drainage between 2005 and 2011.

The risk factors for bile leakage have been already extensively described in several studies $[1,5,11-16]$. Reported independent factors that were correlated with the occurrence of bile leakage were: (1) exposure of Glisson's sheath on the cut surface (caudate lobectomy, central bisectionectomy, and right anterior sectionectomy); (2) resection of segment 4 ; (3) a cut surface area $\geq 57.5 \mathrm{~cm}^{2}$; (4) repeated hepatectomy; (5) intraoperative blood loss $\geq 775$ $\mathrm{ml}$; (6) intraoperative bile leakage; (7) prolonged operative time $\geq 300 \mathrm{~min}$; (8) peripheral cholangiocarcinoma, and (9) preoperative chemoembolization. Bile leakage was also associated with male gender, advanced age, tumor size, major hepatectomy, right-sided hepatectomy, left hepatectomy extended to segment 1 , surgical irradicality, duration of vascular occlusion, and red cell transfusion $[1,5,11-16]$. In our study, relaparotomy was the only independent significant risk factor associated with bile leakage, a similar finding as found in the studies of Hayashi et al. [12] and Yoshioka et al. [16]. However, our multivariate analysis is based on small sample sizes (patients with bile leakage), resulting in possible bias.

Fibrin sealants have become widely used as topical hemostatic agents in liver surgery. However, the additional value to reduce biliary leakage is still controversial. A prospective, randomized controlled study showed that there was no difference in postoperative outcomes between patients who underwent liver resection with and without application of fibrin sealant [17]. There is no evi- 
dence at the moment for routine use of fibrin sealant, which is supported by the abovementioned study. However, usually, the use of a fibrin sealant is determined by the surgeon's preference.

In conclusion, the incidence of posthepatectomy biliary leakage has been decreasing over time (fig. 2); however, it is still a common complication after liver resection. PTD and/or endoscopic stenting are effective in the treatment of most cases of biliary leakage in patients without $\mathrm{HJ}$. Percutaneous abdominal drainage for bile collections is increasingly being performed. Treatment of the leak via PTD is also being increasingly adminis- tered, whereas the number of cases of endoscopic drainage is decreasing. Surgical treatment is required when conservative treatment or radiological management fails. The incidence of relaparotomies has not changed; however, mortality seems to have declined over time. No mortality has been reported in patients with biliary leakage in the last period (2005-2011). Prompt percutaneous, transhepatic biliary drainage is the treatment of choice for bile leakage after $\mathrm{HJ}$ in combination with liver resection, and can be performed safely without the risk of mortality or the need for additional relaparotomies.

\section{References}

1 Capussotti L, Ferrero A, Vigano L, Sgotto E, Muratore A, Polastri R: Bile leakage and liver resection: where is the risk? Arch Surg 2006; 141:690-694.

-2 Tanaka S, Hirohashi K, Tanaka H, Shuto T, Lee SH, Kubo S, Takemura S, Yamamoto T, Uenishi T, Kinoshita H: Incidence and management of bile leakage after hepatic resection for malignant hepatic tumors. J Am Coll Surg 2002;195:484-489.

$\checkmark 3$ Yamashita Y, Hamatsu T, Rikimaru T, Tanaka S, Shirabe K, Shimada M, Sugimachi K: Bile leakage after hepatic resection. Ann Surg 2001;233:45-50.

4 Erdogan D, Busch OR, Gouma DJ, van Gulik TM: Prevention of biliary leakage after partial liver resection using topical hemostatic agents. Dig Surg 2007;24:294-299.

$\checkmark 5$ Erdogan D, Busch OR, van Delden OM, Rauws EA, Gouma DJ, van Gulik TM: Incidence and management of bile leakage after partial liver resection. Dig Surg 2008;25:6066.

6 Koch M, Garden OJ, Padbury R, Rahbari NN, Adam R, Capussotti L, Fan ST, Yokoyama Y, Crawford M, Makuuchi M, Christophi C, Banting S, Brooke-Smith M, Usatoff V, Nagino M, Maddern G, Hugh TJ, Vauthey JN, Greig P, Rees M, Nimura Y, Figueras J, DeMatteo RP, Buchler MW, Weitz J: Bile leakage after hepatobiliary and pancreatic surgery: a definition and grading of severity by the International Study Group of Liver Surgery. Surgery 2011;149:680-688.
7 Dindo D, Demartines N, Clavien PA: Classification of surgical complications: a new proposal with evaluation in a cohort of 6336 patients and results of a survey. Ann Surg 2004;240:205-213.

$>8$ Ferrero A, Russolillo N, Vigano L, Sgotto E, Lo TR, Amisano M, Capussotti L: Safety of conservative management of bile leakage after hepatectomy with biliary reconstruction. J Gastrointest Surg 2008;12:2204-2211.

-9 Nagino M, Nishio H, Ebata T, Yokoyama Y, Igami T, Nimura Y: Intrahepatic cholangiojejunostomy following hepatobiliary resection. Br J Surg 2007;94:70-77.

10 Antolovic D, Koch M, Galindo L, Wolff S, Music E, Kienle P, Schemmer P, Friess H, Schmidt J, Buchler MW, Weitz J: Hepaticojejunostomy - analysis of risk factors for postoperative bile leaks and surgical complications. J Gastrointest Surg 2007;11:555-561.

11 Ishii H, Ochiai T, Murayama Y, Komatsu S, Shiozaki A, Kuriu Y, Ikoma H, Nakanishi M, Ichikawa D, Fujiwara H, Okamoto K, Kokuba Y, Sonoyama T, Otsuji E: Risk factors and management of postoperative bile leakage after hepatectomy without bilioenteric anastomosis. Dig Surg 2011;28:198-204.
12 Hayashi M, Hirokawa F, Miyamoto Y, Asakuma M, Shimizu T, Komeda K, Inoue Y, Arisaka Y, Masuda D, Tanigawa N: Clinical risk factors for postoperative bile leakage after liver resection. Int Surg 2010;95:232-238.

13 Lee CC, Chau GY, Lui WY, Tsay SH, King KL, Loong CC, Hsia CY, Wu CW: Risk factors associated with bile leakage after hepatic resection for hepatocellular carcinoma. Hepatogastroenterology 2005;52:1168-1171.

14 Nagano Y, Togo S, Tanaka K, Masui H, Endo I, Sekido H, Nagahori K, Shimada H: Risk factors and management of bile leakage after hepatic resection. World J Surg 2003;27:695698.

15 Sadamori H, Yagi T, Matsuda H, Shinoura S, Umeda Y, Yoshida R, Satoh D, Utsumi T, Ohnishi T: Risk factors for major morbidity after hepatectomy for hepatocellular carcinoma in 293 recent cases. J Hepatobiliary Pancreat Sci 2010;17:709-718.

16 Yoshioka R, Saiura A, Koga R, Seki M, Kishi Y, Yamamoto J: Predictive factors for bile leakage after hepatectomy: analysis of 505 consecutive patients. World J Surg 2011;35: 1898-1903.

17 Gonzalez HD, Figueras FJ: Topical hemostatic devices in surgery: between science and marketing (in Spanish). Cir Esp 2009; 85(suppl 1):23-28. 